\title{
O corpo coletivo e os afetos: um olhar sob os movimentos feministas na América Latina
}

\author{
The collective body and affections: a look at feminist
} movements in Latin America

El cuerpo colectivo y los afectos: una mirada a los movimientos feministas em América Latina

\section{Camila Carolina Hildebrand Galetti}

ORCID: 0000-0003-2364-2519

Mestra e doutoranda em Sociologia pelo Programa de Pós-graduação em Sociologia, Universidade de Brasília (UnB), Brasil. E-mail: camilagaletti@ hotmail.com

\section{RESENHA}

GAGO, Verónica (2020), A potência feminista ou o desejo de feminista transformar tudo. São Paulo, Editora Elefante, p. 321.

Publicado em espanhol pela editora Tinta Limón Ediciones (2019) e, no ano seguinte, em 2020 traduzida para o português pela Editora Elefante, o livro A potência feminista ou o desejo de feminista transformar tudo propõe a análise da relevância e do protagonismo dos movimentos feministas na América Latina, mais especificamente na Argentina, a partir de mobilizações como o Nosotras paramos, Ni una menos, El violador eres tu, da última década. A cientista política, militante e professora na Universidad de Buenos Aires, Verónica Gago, entrelaça suas experiências na condição de docente e ativista, para mostrar o que há de novidade nas novas formas de articulação das pautas das mulheres, bem como da ofensiva da 
reação conservadora pavimentada pelo neoliberalismo, que demonstrou a necessidade de pensar sobre as crises econômicas, financeiras, políticas, institucionais e coloniais.

O título demonstra os caminhos postulados pela autora a partir do conceito de potência, pois este se refere a uma teoria do poder que está em disputa, afinal, os processos políticos continuam em aberto. Tal contexto demanda dos movimentos feministas massividade e radicalidade para a consolidação de uma contraofensiva neoliberal.

Gago baseia-se nas teorias feministas a partir de autoras como Angela Davis e Silvia Federici para, de certa forma, redefinir o conceito de greve, na tentativa de "cartografar a prática e a política feminista que no tempo presente toma massivamente às ruas" ${ }^{1}$. Nesse sentido, em diversos momentos, A potência feminista dialoga com o livro Feminismo para os 99\%: um manifesto, escrito por Cinzia Arruzza, Nancy Fraser e Tithi Bhattacharya, e lançado pela Editora Boitempo em 2019. Verónica Gago aproxima-se de tais autoras na obra, pois demonstram a necessidade da construção de um movimento feminista massivo e radical. $\mathrm{O}$ qual deve ter como horizonte a emancipação das mulheres, além de ressaltar as problemáticas imbricadas no feminismo liberal, esse que se contenta com uma mínima representatividade das mulheres nos altos escalões das corporações.

Gago pontua, desde o início de sua análise, a importância da tríade trabalho, território e conflito, para se pensar as múltiplas violências às quais mulheres são acometidas cotidianamente. Para isso, cabe ressaltar os dois extremos que perpassam tal realidade: a violência que funda - amparada na consolidação do capitalismo e do quanto o patriarcado foi essencial, reduzindo as mulheres, invisibilizando o trabalho reprodutivo, afetivo e de cuidado. E a violência que conserva - a que reproduz e não questiona, as assimetrias de gênero e as explorações, legitimadas pelo neoliberalismo. Para Gago (2020:96), “a dimensão da violência contra as mulheres é fundamental para entender uma linha entrelaçada de violência que tem relação com o modo como se reconfigura hoje a exploração e a extração do valor".

É interessante ressaltar a preocupação de Gago sobre a questão da violência. A mesma afirma a necessidade de ir além de catalogar as mulheres como vítimas. Parafraseando a historiadora Federici (2011), quando essa fala sobre o "estado de guerra permanente às mulheres", Gago reitera que pluralizar não é apenas fazer uma quantificação, uma lista de violências. É bem mais denso do que isso, propondo cartografar a simultaneidade da violência e sua inter-relação com o sistema capitalista, ao trabalho doméstico invisibilizado e outras diversas formas de exploração que violentam as mulheres (Gago, 2020:72).

\footnotetext{
${ }^{1}$ Cabe ressaltar que, no ano em que este livro foi escrito (2019), não se enfrentava a pandemia do covid-19, o que facilitava a ocupação das ruas via movimentos feministas.
} 
A discussão feita em A potência feminista proporciona-nos diversas entradas de discussão, apresenta como se deram as movimentações \#NosotrasParamos, \#NiUnaMenos, a \#LainternaciolnalFeministas, dentre outras mobilizações impulsionadas por ativistas feministas na Argentina. Dessa forma, é possível avançar as grandes e atuais preocupações da agenda feminista comprometida com as mulheres, lésbicas, trans e travestis, sob um caráter classista e antirracista. Pois, as modalidades de crimes contra esses grupos tem se intensificado nos últimos anos, principalmente após uma reação conservadora nos países da América Latina, não tão somente, mas também em nível global.

O livro é dividido em oito capítulos, o capítulo um, \#NosotrasParamos: por uma teoria política da greve feminista, tem como fio condutor o trabalho em perspectiva feminista, que permite pensar uma política de reprodução da vida que torna e atravessa o trabalho doméstico, social, camponês, suburbano" (p. 26). Com isso, a greve laboral e a greve existencial são discutidas para problematizar a articulação entre capitalismo, colonialismo e patriarcado e a necessidade de redefinição da categoria trabalho sob uma perspectiva feminista. Gago aponta, como saída, a construção de um feminismo popular e antineoliberal, que tem como uma das finalidades expandir o conceito de corpo, combatendo o ideário de corpo individual, criado pelo neoliberalismo, e de objeto de direitos liberais, para se tornar um corpo coletivo, múltiplo.

No capítulo dois, Violências: há uma guerra no e contra o corpo das mulheres?, a discussão gira em torno de como as inúmeras violências atravessam as mulheres. Ao questionar o porquê matam mulheres, a cientista política traz para a discussão os escritos de Rita Segato (2014), a qual se debruça a pensar novas formas de guerra contra as mulheres. Segundo essa autora, os pactos e mandatos de masculinidade funcionam e se retroalimentam a partir de uma estrutura patriarcal, que conserva o homem em um lugar de privilégio. Porém, com os avanços dos movimentos feministas, "as masculinidades desvalorizadas estão em busca desesperada e violenta de reestruturação" (Segato, 2014:85).

O capítulo três, Corpo-território: o corpo como campo de batalha, evidencia a disputa intensa pelo corpo feminino, que se torna território de disputa pelo Estado, Igreja e pelo Patriarcado. Com isso, os feminismos indígenas e comunitários, ao falar de corpo-território, estabelecem para todos os feminismos uma exigência: a descolonização como dimensão prática (Gago, 2020:112). A partir de movimentações como a Maré verde ${ }^{2}$, as feministas

\footnotetext{
${ }^{2}$ Maré verde é uma mobilização intergeracional que têm ocupado as ruas de cidades como Buenos Aires, Argentina, que vem tramando, aprofundando e organizando laboriosamente o desejo de autonomia sobre os
} 
produziram, segundo Gago, condições para que fosse possível um deslocamento protagonizado por mulheres, ressignificando assim o espaço doméstico - que, a partir do patriarcado, foi estabelecido como um lugar de repressão, violência e horror.

Uma economia feminista que pensa a exploração e extração, evidencia-se no capítulo quatro, demonstrando o quanto o ocultamento da reprodução perpetua as desigualdades de gênero, despolitizando as relações de cuidado e de trabalho reprodutivo. Para que seja possível vislumbrar mudanças quanto a esse aspecto, Gago assinala a necessidade de reconceitualizar a ideia de classe social a partir da economia feminista, que pratica um diagnóstico do diferencial de exploração, que considera a reprodução âmbito central para, a partir daí, investigar e historicizar os modos como se conjugam a exploração e a extração de valor. Cabe ressaltar, na discussão proposta, a relevância da financeirização, que aprofunda o endividamento e a inflação, potencializa o neoliberalismo no sentido de oferecer possibilidades de crédito como plataforma individual de resolução dos problemas dos indivíduos. A dívida se torna mecanismo de coação para aceitar qualquer condição de trabalho, aumentando assim a precarização e pobreza.

No capítulo cinco, Assembleias: um dispositivo situado de inteligência coletiva, são problematizadas possíveis novas formas de contrapoder e, nesse escopo, segundo a autora, as assembleias estão produzindo novas formas a partir de uma soberania popular que desafia a fé estatal como monopólio da política, de insurgências que renovam as dinâmicas de decisão e autonomia (Gago, 2020:195). Nesse sentido, as greves resultam em maior número de assembleias, as quais potencializam a inteligência e a decisão coletiva. Nas palavras da autora, "A assembléia, em suas diversas versões, nos transforma porque funciona como espaço de processamento coletivo dos padecimentos do ajuste e da crise, das injustiças históricas" (ibidem:196). Com isso, esse espaço torna-se singular para as tomadas de decisão e fortalecimento do corpo coletivo.

O capítulo seis, \#LaIternacionalFeminista, é demonstrada a relevância do internacionalismo no movimento feminista atual, que proporciona uma projeção das massas, ampliando também as pautas e conceitos ao compreender as mulheres multifacetadas, sem uma categoria única de ser mulher; logo, as opressões são múltiplas. A partir disso, Gago (2020:217) questiona: como se expressa o transnacionalismo no movimento feminista? O transnacionalismo evidenciado pela autora qualifica cada situação como concreta, no sentido de criar uma ubiquidade prática, ou seja, o que acontece em um determinado espaço ressoa

corpos e territórios femininos. Disponível em https://catarinas.info/mare-verde-a-trajetoria-das-argentinas-naluta-pela-legalizacao-do-aborto/. Acesso em 10 de jan. 2021. 
em outros, demonstrando o caráter de conexão entre as lutas, apesar de suas especificidades. Com isso, estabelecem-se novos parâmetros, categorias, e medidas para viabilizar uma política coletiva.

Um exemplo disso são as manifestações \#NiUmaMenos, que aconteceu em Buenos Aires, em 2018 e demonstrou a força das ativistas argentinas em organização e ocupação das ruas. Enquanto isso, milhares de mulheres, lésbicas, trans e travestis (se for especificar orientação e identidade de gênero, sugiro especificar de todas: mulheres cis hétero, lésbicas trans.) denunciavam o feminicídio como crime de Estado, e a ameaça permanente representada pelas tentativas de sequestro que ocorriam no metrô (Gago, 2020:225). Enquanto isso, no Chile, a coordenação do 8 de março não parava de crescer, aos gritos de: "La huelga feminista va!"3. Essas mobilizações, dentre outras que ocorreram na Bolívia, Brasil e Peru, demonstram a potência das alianças transversais e diversas, bem como a possibilidade de que uma greve geral pode impulsionar os movimentos feministas a partir da capacidade de afetação e de solidariedade internacional.

No capítulo sete, e penúltimo, Contraofensiva: o espectro do feminismo, a discussão concentra-se em dissecar a maneira em que o feminismo tem sido construído enquanto um inimigo interno, e como tem se dado a corrida pela desestabilização feminista frente a todos os avanços da agenda feminina das últimas décadas, como a lei do feminicídio etc. Sobre esse aspecto, cabe ressaltar que tal contraofensiva não possui caráter de novidade. No decorrer da história, evidencia-se que, conforme as lutas das mulheres avançam, em consonância, aumenta a resistência pelos direitos conquistados. Para ilustrar tal realidade, Gago resgata o contexto político brasileiro a partir da posse à presidência de Jair Bolsonaro, que, em seus poucos minutos de discurso, ressaltou diversas pautas que embasam a extrema-direita, como o combate à suposta ideologia de gênero.

A moralidade é um dos fios condutores que pavimenta o combate ao feminismo nessa lógica. Alinhando-se com o neoliberalismo, no sentido de atribuir a um modelo único de família - heterossexual - a responsabilidade diante do despojo da infraestrutura pública, o giro conservador busca de diversas formas desmantelar direitos humanos e reduzir as mulheres ao confinamento do lar. Isso acontece porque o movimento feminista, em toda a sua diversidade, politizou de maneira nova e radical a crise da reprodução social como crise civilizatória, e ao mesmo tempo, como crise da estrutura patriarcal da sociedade (Gago, 2020:268).

\footnotetext{
${ }^{3}[\ldots]$ A greve feminista vai! (tradução da autora da resenha).
} 
O capítulo oito, e último, Oito teses sobre a revolução feminina, detêm-se a materializar algumas novidades dos movimentos feministas que se apresentam no atual contexto. Para isso, a autora mobiliza a ferramenta da greve feminista, que, segundo ela, permite o mapeamento de novas formas de exploração dos corpos e dos territórios em uma perspectiva de visibilização (Gago, 2020:275). Nesse capítulo, é reconhecido o trabalho territorial, reprodutivo, afetivo e doméstico, demonstrando assim como se entrelaçam as violências patriarcais, coloniais e capitalistas.

Verónica Gago, em sua obra A potência feminista, permite-nos vislumbrar possibilidades tangíveis para que, de fato, o feminismo seja como caixa de ressonância de todas as lutas (Gago, 2020:209). Com isso, se configura como uma contra resposta ao neoliberalismo, que ora se apropria e modifica algumas pautas feministas a partir do feminismo liberal, ora combate tais pautas. O resultado disto é a consolidação de um antifeminismo que se demonstra principalmente a partir de atores e atrizes da extrema-direita.

Para que a luta feminista na atual realidade seja eficaz, a ideia de solidariedade deve estar em evidência, como aparece em diversos momentos no livro. No sentido de demonstrar uma política que priorize a construção de alianças, sem desconhecer as diferenças e conflitos, que tenha como ponto de partida o anticapitalismo, o antirracismo e a luta contra o patriarcado.

Cabe ressaltar as dificuldades de analisar os fenômenos que estão em curso - como as investidas neoconservadoras e enfraquecimento de pautas feministas, pois, apesar da cadeia de causalidades preparar o cenário que vivenciamos, é necessário destacar que isso, por si só, não fornece aportes teóricos para explicar a totalidade. Gago, porém, descortina questões caras às mulheres, e que as atravessam cotidianamente, o que aponta para estratégias de formas de organização. Como, por exemplo, a necessidade da construção do corpo coletivo, a redefinição da categoria trabalho e a radicalidade na forma das mulheres se colorem tanto no espaço doméstico, quanto no público.

Tendo em vista a reação conservadora vislumbrada em nível internacional, a partir de governos neoliberais e neoconservadores, o livro de Verónica Gago pode ser lido como um respiro, no sentido de compreendermos a força e a relevância dos movimentos feministas, nominando as violências que acometem as mulheres cotidianamente.

O desejo de transformar tudo talvez ocorre quando há compreensão da totalidade das formas de opressão, quando se nomeiam os incômodos, violências e se propõem novas dinâmicas, que tem como finalidade a emancipação dos indivíduos, de forma coletiva. Afinal, o corpo revela-se composição de afetos, recursos e possibilidades que não são "individuais", 
mas se singularizam, por que passam pelo corpo de cada um, na medida em que cada corpo nunca é só "um", mas o é sempre com outros, e com outras forças também "não humanas" (Gago, 2020:107).

\section{Referências}

ARRUZZA, Cinzia; BHATTACHARYA, Tithi; FRASER, Nancy (2019), Feminismo para os 99\%: um manifesto. São Paulo, Boitempo Editorial.

FEDERICI, Silvia (2011), On Affective Labor, in Peters, Michael A.; Bulut, Ergin (Orgs.). Cognitive Capitalism, Education and Digital Labor. Nova York, Peter Lang, pp. 57-74.

GAGO, Verónica (2020), A potência feminista ou o desejo de feminista transformar tudo. São Paulo, Editora Elefante, p. 321. 